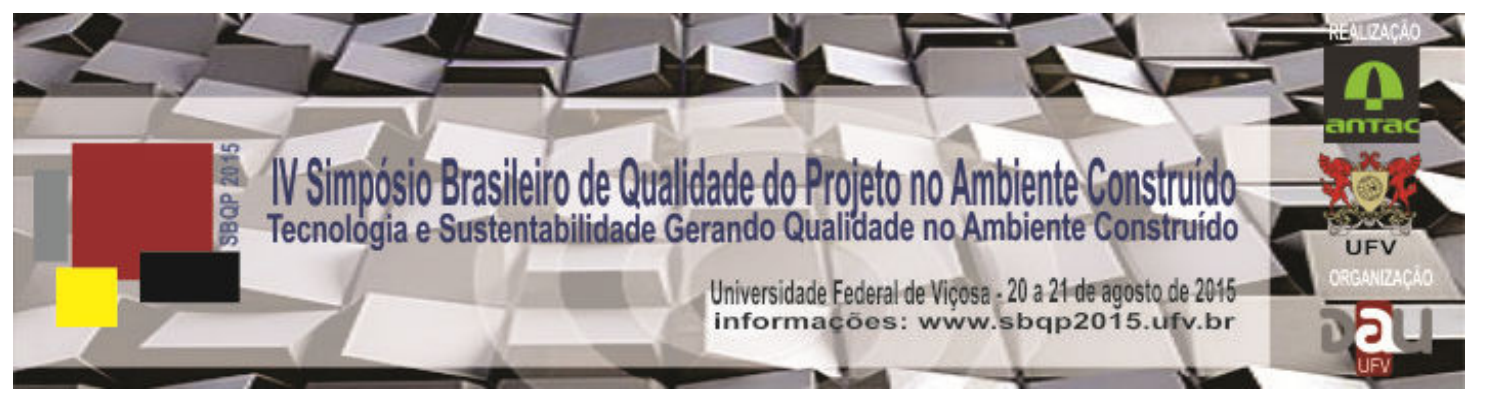

\title{
TECNOLOGIAS NAS SALAS DE AULA E O ENSINO DE PROJETO ARQUITETONNICO'
}

\author{
ZOLENI, Lamim Braz \\ Universidade Federal de Viçosa, zoleni.braz@ufv.br \\ TIBÚRCIO, Túlio Márcio de Salles \\ Universidade Federal de Viçosa, tiburcio@ufv.br
}

\begin{abstract}
RESUMO
Entre as décadas de 70 E 80 , as tecnologias da informação e comunicação se desenvolveram de forma acelerada por todo o globo. O mundo contemporâneo é, constantemente, influenciado pelas novas Tecnologias da Informação e Comunicação (nTICs). Essas tecnologias adentraram todas as esferas das atividades humanas, sendo perceptíveis na arquitetura. Os aparatos tecnológicos são grandes potencializadores do ambiente construído e das tarefas desenvolvidas pelo homem, embora possam ser também inibidores. Tendo em vista esse contexto, o presente artigo tem por objetivo investigar e discutir os espaços das salas de aula onde são ministradas disciplinas de Projeto Arquitetônico II e IV pertencentes a duas instituições federais de ensino superior. Esse trabalho é parte de pesquisa de mestrado, em desenvolvimento, intitulada Impacto da Inserção de novas tecnologias em Cursos de Arquitetura e Urbanismo de Instituições Federais de Ensino. A metodologia utilizada inclui dois estudos de casos, permitindo a utilização de vários métodos de investigação. No desenvolvimento da pesquisa de mestrado foram utilizados os seguintes métodos: análise documental, questionário, mapa comportamental e mapeamento tecnológico dos ambientes das salas de aula investigadas. Esse artigo abordará o mapeamento tecnológico das salas de aula das disciplinas PII e PIV de duas instituições tratadas aqui como A e B. Como resultados desta etapa da pesquisa, constatou-se que os ambientes investigados são ambientes híbridos contendo tecnologias tradicionais e novas. Isto mostrou que os espaços estão em transformação para atender essa sociedade emergente que é informatizada, em rede, na qual os avanços tecnológicos são contínuos.
\end{abstract}

Palavras-chave: Ambientes de Aprendizagem, Escolas de Arquitetura, TICs, Projeto Arquitetônico.

\begin{abstract}
Between the 70's and 80's, the information and communication technologies have developed at an accelerated rate across the globe. The contemporary world is constantly influenced by new information and communication technologies (nICTs). These technologies stepped into all spheres of human activities, being noticeable in architecture. Technological devices are great enhancers of the built environment and
\end{abstract}

\footnotetext{
1 Trabalho apresentado no IV SBQP 2015. Universidade Federal de Viçosa.

Disponível em: doi> http://dx.doi.org10.18540/2176-4549.6047
} 
the tasks performed by humans, although they can also be inhibitors. Given this context, this paper aims to investigate and to discuss the spaces of the classrooms where subjects of Architectural Design II (PII) and IV (PIV) are taught in two federal institutions of higher education in Minas Gerais. This work is part of master's research, under development, Impact of the Insertion of New Technologies in Architecture and Urbanism Programs in Federal Education Institutions in Brazil. The methodology includes two case studies, allowing the use of various methods of investigation. In developing the master's research the following methods were used: documental analysis, questionnaire, behavioral map and technology mapping of the classrooms environments being investigated. This paper will address the technological mapping of the classrooms where PIl and PIV where though in two different institutions treated here as $A$ and $B$. As a result of this phase of the research, it was found that the investigated environments are hybrid environments containing traditional and new technologies. This showed that the spaces are changing to meet this emerging society that is computerized, networked, in which technological advances are continuous.

Keywords: Learning Environments, Architecture Schools, TICs, Architectural Design

\section{INTRODUÇÃO}

Bokc, Furtado e Teixeira (2009) afirmam que a sociedade contemporânea vive a era da Terceira Revolução Industrial acarretada por fortes avanços tecnológicos iniciados na década de 1950 e intensificados em 1970. O acontecimento decisivo foi a criação do chip eletrônico e a possibilidade de diminuição do tamanho dos equipamentos. Essa evolução tecnológica ocorreu nas áreas de telecomunicação, cibernética, aeroespacial e microeletrônica. Houve verdadeira revolução tecnológica focada na Tecnologia da Informação e Comunicação (TIC).

Segundo Castells (1999), o mundo atual é informatizado, globalizado, em rede, marcado por tecnologias cada vez mais inovadoras e avançadas que está impactando a vida social, as atividades humanas, a produção do ambiente construído. Embora a tecnologia tenha penetrado no seio da sociedade não a determina e nem a sociedade determina o curso da mudança tecnológica porque muitos fatores interferem no processo de descoberta científica como inovação tecnológica e aplicações sociais de maneira que o resultado do produto final depende de um padrão interativo complexo. Tibúrcio (2009) afirma que as novas tecnologias impactam o processo ensino-aprendizagem e - espaço das salas de aula onde as nTICs estão cada vez mais inseridas. Diante dessa realidade que ocorre praticamente em toda escala mundial, os edifícios estão se tornando cada vez mais complexos. Para Pádua (2006) a complexidade dos edifícios é possível graças à automatização e as novas tecnologias compondo o ambiente de forma integrada.

De acordo com Castells (1999), escolas e universidades não acompanham a lógica virtual na mesma proporção apesar da previsibilidade e da universalidade do uso de computadores nos países desenvolvidos. O autor afirma que essas instituições de ensino formal não sumirão no espaço virtual. Isso não acontecerá no ensino fundamental e médio porque são espaços de desenvolvimento infantil e espaço de socialização. No ensino universitário, a excelência da educação é, e continuará sendo por um longo tempo, ligada a interação pessoal. Castells (1999) ressalta que por esse, a experiência de universidades à distância em larga escala independente da qualidade, ruim na Espanha e boa na Grã-Bretanha, são uma segunda opção de educação. Essa modalidade de ensino pode ser considerada como um futuro sistema 
aperfeiçoado de educação de jovens e adultos. No entanto, não substitui as instituições de ensino superior. Castells (1999) destaca ainda que o que vem surgindo nas universidades de qualidade é a combinação do ensino a distância com o ensino presencial.

\section{NOVAS TECNOLOGIAS NO AMBIENTE CONSTRUÍDO}

De acordo com Tibúrcio, Pieroni e Costa (2013) o mundo globalizado, em rede e com tecnologias cada vez mais avançadas que interferem na sociedade, na maneira de edificar, no modo de vida das pessoas.

Tibúrcio, Gonzaga e Rocha (2013) afirmam que os princípios da inteligência predial, as novas tecnologias estão invadindo os ambientes educativos. Os quadros negros estão sendo substituídos por quadros interativos, os livros didáticos por laptops e CD ROMS, as transparências pelo uso do programa Power Point e similares. Tibúrcio (2009) em investigação realizada na Inglaterra, identificou que os ambientes das salas de aula se constituíam em espaços atrativos, flexíveis e ajustáveis para satisfazer diferentes idades e tamanhos. Observou também práticas sustentáveis no projeto da sala de aula e do mobiliário. A Figura 1 mostra exemplos de vários ambientes de aprendizagem da sociedade informatizada. São salas de aula de um programa do governo britânico, intitulado Classroom of the Future, onde as salas de aula foram projetadas e construídas para testar novas possibilidades de ensino e aprendizagem, com uso das novas tecnologias inseridas na sala de aula. Este grande experimento levantou questões sobre o espaço da sala de aula e as tecnologias.

\section{FIGURA 1 - Salas de Aulas do Futuro (Classroom of the Future) - Inglaterra}

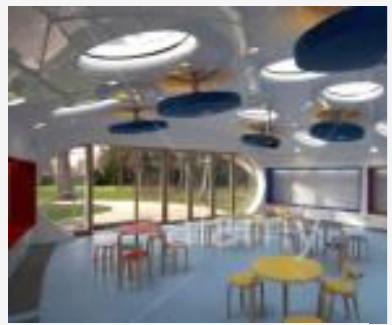

Richmond Fonte: DFES, 2003

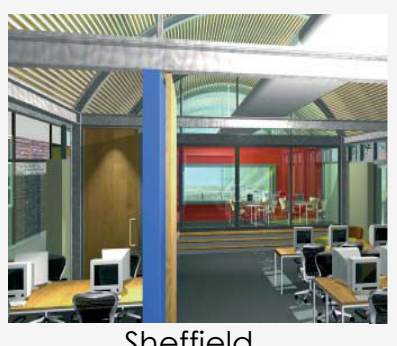

Sheffield Fonte: DFES, 2003

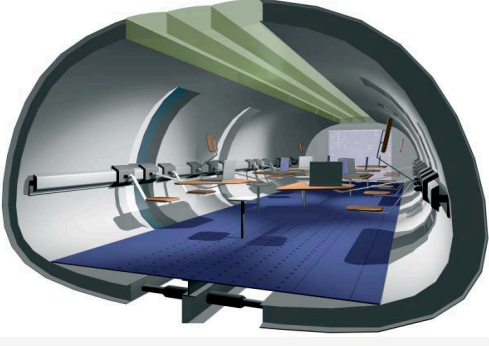

Camdem Fonte: DFES, 2003

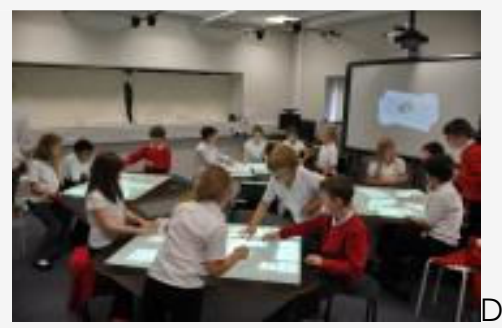

urham Fonte: DFES, 2003

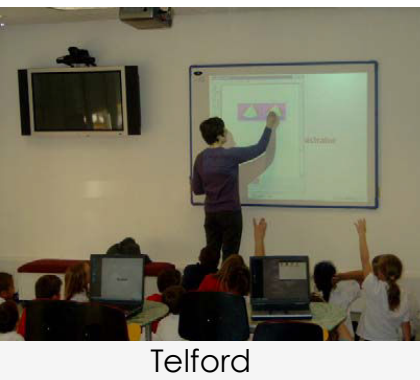

Fonte: Acervo Túlio Tibúrcio

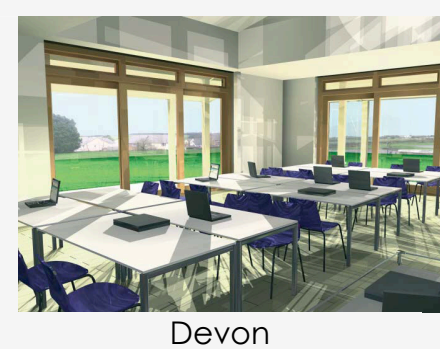

Fonte: DFES, 2003

Na Figura 2 outros exemplos mais recentes de ambientes de aprendizagem tecnológicos são mostrados. São diferentes espacializações de salas de aula em função de novas tecnologias e modos de ensinar e aprender. 


\section{FIGURA 2 - Outras propostas de conformação de salas de aulas do futuro}

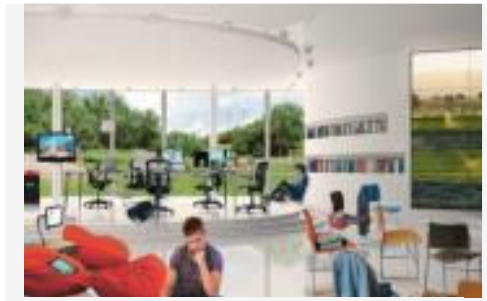

A vision for a classroom of the future

Fonte:

http://i.dailymail.co.uk

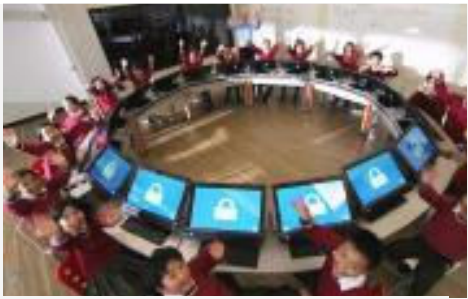

HP's Classroom on the future in Taiwan

Fonte: http://i.ytimg.com

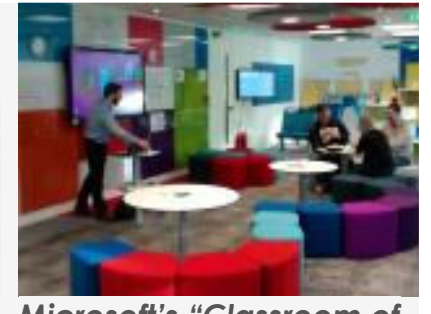

Microsoft's "Classroom of the Future in London

Fonte:

http://www.ebuyer.com

Bordwell, citado em Crosbie (2001), argumenta que "O desafio dos educadores, planejadores e arquitetos para integrar as tecnologias da instrução é reconhecer a magnitude das mudanças que poderão ocorrer nos próximos 25 anos e construir escolas que irão atender estes desafios" (p.8). Para Kenski (2007) as ferramentas digitais atuais proporcionam um desenvolvimento cognitivo maior e melhor; e Kowaltowski (2011) afirma que o conforto ambiental, o fator emocional e os equipamentos tecnológicos influenciam no aprendizado do sujeito. Kowaltowski (2011) ressalta a necessidade da presença da tecnologia nos espaços escolares. A autora afirma que o sistema wireless deve compor o ambiente escolar com a finalidade de proporcionar o acesso a informação em todo ambiente escolar com cantos que permitem aos educandos lerem, sentar e usar laptops.

Para o ensino de arquitetura, Segundo e Romano (2010) afirmam que os sistemas de ferramentas computacionais CAD (Computer Aided Design) que apenas substituíam as técnicas tradicionais de representação gráfica nas primeiras versões, hoje são ferramentas que participam de todo o processo projetual, desde a sua concepção até a execução do objeto arquitetônico.

De acordo com Segundo e Romano (2010) o ensino e o ambiente de projeto arquitetônico devem conter tecnologias tradicionais e novas. As salas de aula precisam acompanhar a nova realidade global. Para Carvalho e Savignon (2012) os equipamentos em classes e laboratórios devem ser atualizados e de qualidade. As ferramentas tradicionais são muito importantes para a formação do aluno também. De acordo com Segundo e Romano (2010) elas facilitam compreender melhor o problema projetual e Carvalho e Savignon (2012) afirmam que o desenho manual ajuda a definir a peculiaridade do traço de cada estudante de arquitetura.

De acordo com Malard (2005) é necessário resgatar e atualizar o primitivo papel da arquitetura e adequá-la aos nossos dias atuais, aos adeptos contemporâneos. Para a autora "alguns e poucos arquitetos começam a propor objetos arquitetônicos híbridos, que, assumindo as novas formas de mediação tecnológica, buscam a instauração de um lugar que seja mais adequada aos nossos dias" (MALARD, 2005, p. 77).

Essas discussões sobre o impacto das tecnologias no espaço físico e no processo de ensino-aprendizagem são fundamentais hoje, considerando a revolução digital que a sociedade enfrenta. Torna-se necessário avaliar e repensar os ambientes de aprendizagem. Tibúrcio, Gonzaga e Rocha (2013) 
investigaram salas de aula de uma instituição federal com esse olhar das novas tecnologias, com o objetivo de identificar demandas de novos ambientes de aprendizagem e adaptações necessárias em espaços existentes.

Esta pesquisa corrente analisa algumas salas dedicadas ao ensino de arquitetura com o olhar sobre a relação entre novas tecnologias-novos espaços-novas pedagogias. Este estudo tem objetivo de entender se e como os espaços para a formação dos arquitetos estão se modificando ou não para atender a demanda de uma produção arquitetônica digital e tecnológica.

\section{METODOLOGIA}

A pesquisa de mestrado consiste em dois estudos de casos, duas escolas de arquitetura em duas universidades diferentes, com abordagem quantitativa e qualitativa. Tem como fonte de evidência os métodos questionário, levantamento documental, mapeamento tecnológico das salas de aula e o mapa comportamental que é embasado na psicologia ambiental e realizado através da observação in loco. A abordagem do primeiro método é quantitativa, do segundo qualitativa e do terceiro quantitativa e qualitativa. $O$ estudo é de caráter descritivo, comparativo e exploratório. A população é composta por 593 sujeitos. A amostra contém 155 sujeitos selecionados intencionalmente.

Esse artigo discute o mapeamento tecnológico realizado através do registro das tecnologias existentes no espaço físico das salas de aula de projeto arquitetônico II e IV (PII e PIV) da Universidade A e Universidade B. Para este mapeamento tecnológico as tecnologias foram categorizadas em tradicionais e novas, assim como móveis e fixas. Foi registrado o que havia de tecnologia no ambiente da sala de aula e mapeadas em croquis de plantas baixas.

\subsection{Mapeamento Tecnológico}

As amostras do objeto de pesquisa são três salas de aula onde as disciplinas pesquisadas, Pll e IV, dos cursos de Arquitetura e Urbanismo das duas instituições de ensino eram ministradas. A escolha das disciplinas justifica-se por serem disciplinas iniciais e intermediárias na grade dos cursos.

O mapa tecnológico possui abordagem descritiva e qualitativa. Os espaços das salas de aula foram visitados, observados e as informações registradas. Procurou-se investigar os detalhes contidos no ambiente, principalmente nos aspectos relacionados às novas tecnologias. Para demonstrar os dados coletados foram feitos registros em plantas baixas e as salas foram fotografadas. Foram identificadas tecnologias tradicionais e novas tecnologias.

\section{RESULTADOS E DISCUSSÕES}

Para as disciplinas Pll e PIV da instituição A, foi utilizada a mesma sala de aula, denominada Sala de Aula $\beta$. Na instituição B, as mesmas disciplinas utilizaram a sala denominada Sala de Aula a sendo que a disciplina PIV também utilizou a Sala de Aula Y.

A Sala de Aula $\beta$ é um espaço bem amplo, de forma retangular, com duas 
portas na parede lateral e janelas na outra lateral que faz parte da fachada frontal. Nessas paredes laterais há tubulações com tomadas, ventiladores e interruptores. Existem tomadas de energia em todas as paredes das salas de aula. Um fator importante observado é que as tomadas não são um elemento tecnológico novo a compor as salas de aula, mas a quantidade e a localização delas no ambiente estão configurando o espaço de maneira diferenciada. Isso pode ser verificado no espaço da Sala de Aula $\beta$ e nas respostas dos questionários aplicados aos alunos e professores, não discutidos aqui, por estar fora da abordagem deste artigo. As tubulações inseridas na sala de aula, foram com o propósito de atender a demanda do uso de laptops pelos alunos durante as aulas. A sala tem um quadro negro (giz) numa extremidade e um quadro branco (pincel) na outra extremidade da sala. Não foram identificados equipamentos fixos na sala. O mobiliário é constituído por pranchetas com réguas paralelas e cadeiras, incluindo mesa do professor. $\mathrm{Na}$ lateral da sala existem bancadas para guardar material e ou elaboração de maquetes.

Os equipamentos móveis identificados são: dois retroprojetores e a tela de projeção que ficam na sala de aula disponíveis para uso. Outros móveis ficam à disposição em sala de apoio, laptop e datashow, que são trazidos pelo funcionário do departamento para cada aula. Também são disponibilizados outros equipamentos (tecnologias) móveis como TV, Vídeo player, CD player, câmeras fotográficas, filmadoras, caixas de som, GPS e lousa digital, caso o professor ou alunos agendem para as aulas. .

A Figura 2 da página 6 mostra o mapa tecnológico da Sala de Aula $\beta$ na forma original da coleta de dados, pela executora do projeto de pesquisa.

O ambiente da Sala de Aula a da instituição B tem formato retangular, é ampla (menor que a da instituição A). Na parede lateral da porta há um interruptor, na parede dos fundos, duas tomadas e na outra lateral estão as janelas com armários embutidos embaixo delas. Na parede frontal tem um quadro branco, duas tomadas e um interruptor. No teto está instalado o datashow, como tecnologias móveis que o departamento dispõe para os professores lecionarem são TV, DVD, computador, datashow, retroprojetor e caixa de som. No piso existe um tablado formado por três peças de madeira. O mobiliário é constituído de pranchetas com e sem réguas paralelas e a mesa do professor. $O$ número de pranchetas com réguas paralelas é maior e as cadeiras da sala são estofadas. A Figura 3 da próxima página representa a Sala de Aula a. Identificou-se a existência de poucas tomadas para uso de laptops ou outros equipamentos.

O ambiente da Sala de Aula y da instituição B tem formato retangular, sendo um espaço menor que a outra sala investigada nesta instituição. Na parede lateral da porta há um interruptor e na parede dos fundos não há nenhuma tomada. Na outra lateral estão as janelas e embaixo delas os armários embutidos. Na parede frontal tem o quadro branco para pincéis e a tela de projeção está acima dele. Há uma extensão, duas tomadas e um interruptor. O datashow fica fixo no teto e existe um tablado no piso feito em madeira. $O$ mobiliário é constituído por pranchetas com réguas paralelas e uma mesa de apoio. As pranchetas tem o mesmo tamanho da Sala de Aula a, mas não há pranchetas sem réguas paralelas. As cadeiras da sala são estofadas e giratórias. A Figura 4 representa a Sala de Aula Y. 
Figura 2 - Mapeamento da Sala de Aula $\beta$

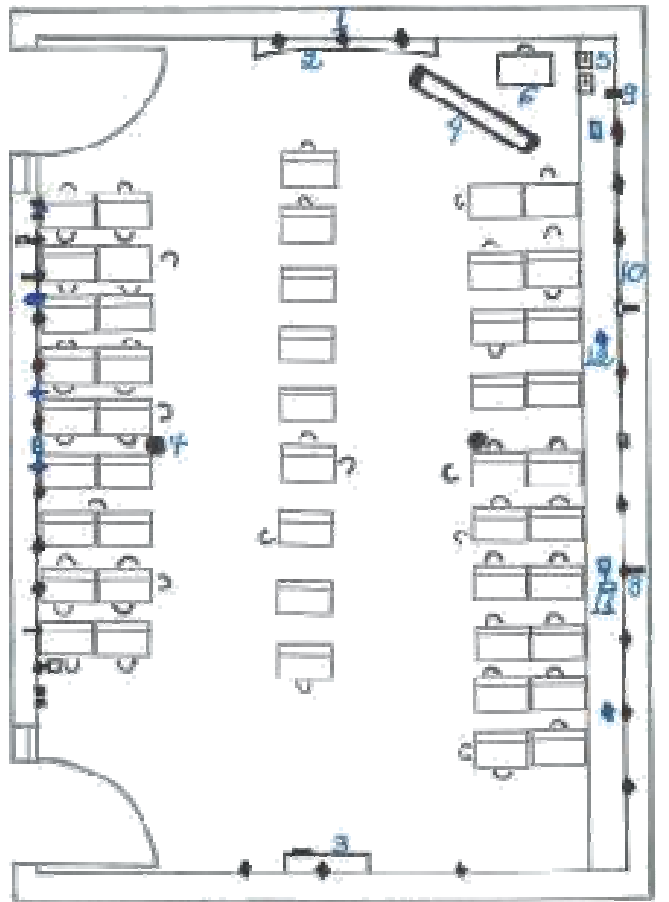

LEGENDA

1- Tomada

2- Quadro negro

3- Quadro branco

4- Tela para projeção

5- Retroprojetor 6- Mesa do professor

7- Pilar

8- Tubulação de tomada com ventilador

9- Interruptor

10- Tubulação

11- Caixa de

tomada vazia

12- Tomada

Fonte: Resultado da Pesquisa (2015)

Figura 3 - Mapeamento da Sala de Aula a

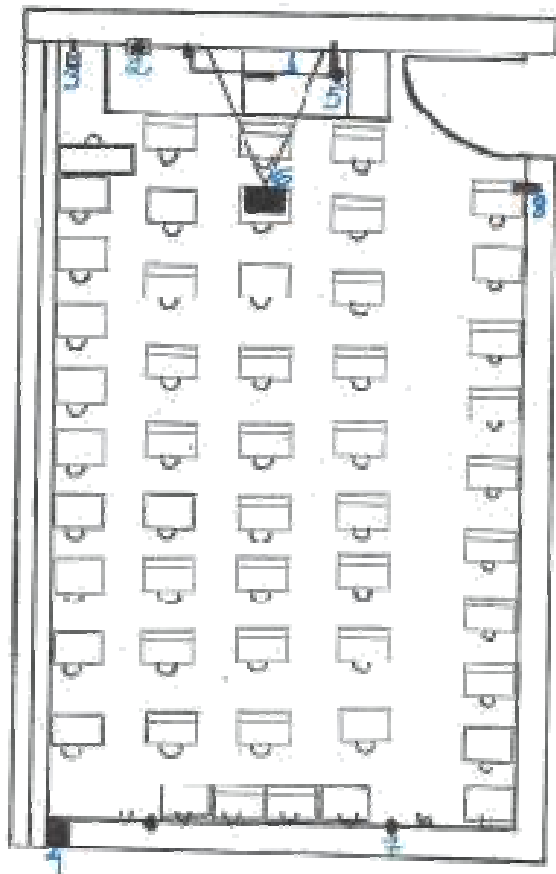

LEGENDA

1- Quadro branco

2- Pia

3- Extensão para datashow

4- Vão

5- Tubulação com interruptor e tomada 6- Datashow fixado no teto

7- Tomada

8- Interruptor

Fonte: Resultado da Pesquisa (2015) 


\section{Figura 4 - Mapeamento da Sala de Aula Y}

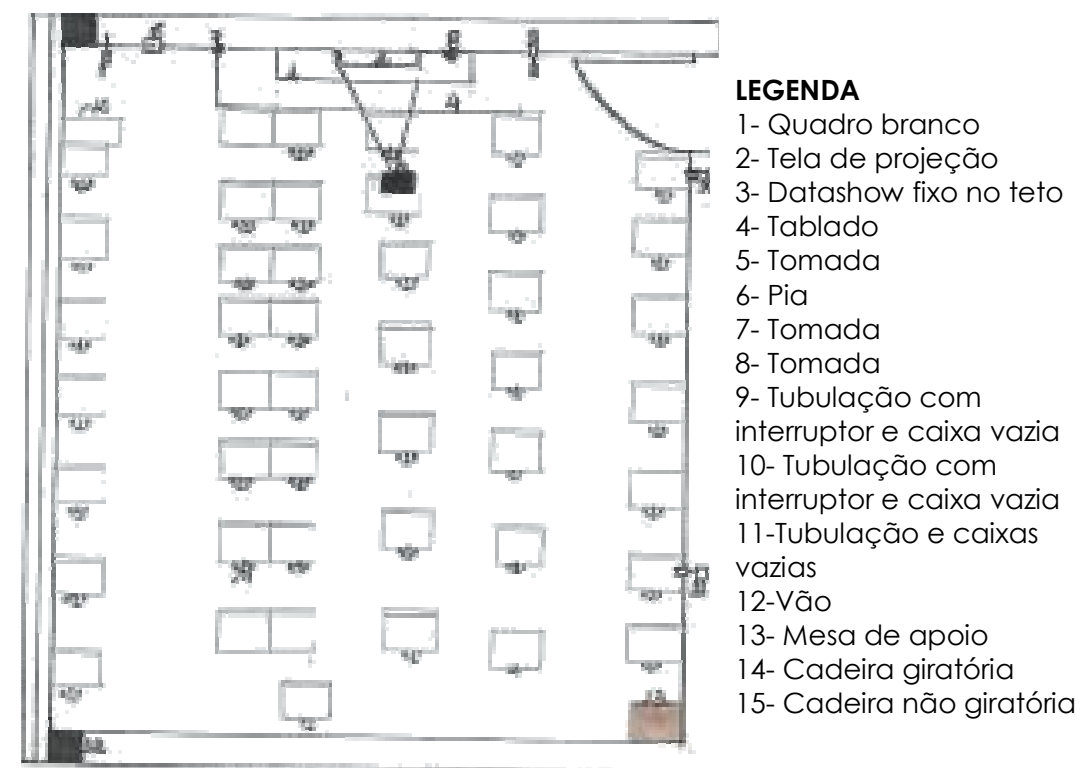

FONTE: Resultado da Pesquisa (2015)

A Sala de Aula $\beta$ faz parte de um edifício moderno e horizontal. Sua configuração espacial mostra adaptações para acompanhar as novas tendências de uma sociedade informatizada ao introduzir no espaço tubulações com várias tomadas para a demanda do uso de computadores. A internet foi também fornecida via rede wireless. O Projeto Político Pedagógico (PPP) do curso de Arquitetura e Urbanismo (2004) da instituição A aborda o espaço, as instalações e os equipamentos disponíveis digitais como datashow, tela de projeção, computadores desktop, software aplicado à Arquitetura e Urbanismo, câmara fotográfica e CDs. O PPP expõe o desejo de formar arquitetos urbanistas hábeis frente aos instrumentos de informática e também acredita no potencial desses equipamentos no processo ensino aprendizagem.

A Sala de Aula a da instituição B faz parte de um edifício mais contemporâneo com uso da estrutura metálica numa forma também mais horizontalizada. Em seu Projeto Político Pedagógico para o curso de Arquitetura e Urbanismo, Vilela, Abecê e Paula et. al (2008) ressaltam a importância e o dever de habilitar e tornar o aluno competente em relação aos instrumentos de informática, mas não cita equipamentos como no curso da instituição A. O que é focado nesse PPP é tecnologia na área de construção civil e principalmente na preservação do patrimônio cultural e da paisagem natural. Como no curso da instituição A, na configuração do espaço da sala de aula há tecnologia digital como o datashow (não tem tela de projeção, que é feita no quadro branco), porém há poucas tomadas espalhadas na sala de aula para a utilização de computadores pelos alunos.

A Sala de Aula $Y$ da instituição B tem praticamente a mesma configuração espacial. A diferença é por ser um espaço menor, ter tela de projeção, ausência de tomadas nos fundos da sala de aula, o tablado é único e as cadeiras são giratórias. Essa sala de aula sofreu um pequeno aumento em seu tamanho. Em todas as salas de aula supracitadas há rede de internet. 
Itlelson, Rivlin, Proshansky (1978) abordam em sua obra resultados e análises realizados através da categorização. A Tabela 1 categoriza as tecnologias inseridas no espaço da sala de aula, identificadas no mapeamento tecnológico, de acordo com as tecnologias tradicionais, novas tecnologias, fixas e móveis.

TABELA 1- Categorização das Tecnologias Identificadas nos Ambientes de Ensino de Projeto Arquitetônico

\begin{tabular}{|c|c|c|c|c|}
\hline \multicolumn{5}{|c|}{ CATEGORIZAÇÃO DAS TECNOLOGIAS IDENTIFICADAS } \\
\hline \multirow[t]{2}{*}{ SALA DE AULA } & \multicolumn{2}{|c|}{ TECNOLOGIAS TRADICIONAIS } & \multicolumn{2}{|c|}{ NOVAS TECNOLOGIAS } \\
\hline & MÓVEIS & FIXAS & MÓVEIS & FIXAS \\
\hline \multirow{11}{*}{$\begin{array}{l}\text { Sala de Aula } \beta \\
\text { Instituição A }\end{array}$} & & & & \\
\hline & & $\begin{array}{l}\text { Quadro } \\
\text { negro }\end{array}$ & Tela projeção & \\
\hline & Giz & & Internet wireless & $\begin{array}{l}\text { Internet } \\
\text { ponto }\end{array}$ \\
\hline & & $\begin{array}{l}\text { Quadro } \\
\text { branco }\end{array}$ & Laptop & \\
\hline & Retroprojetor & & Datashow & \\
\hline & $\begin{array}{l}\text { Pranchetas com } \\
\text { réguas paralelas }\end{array}$ & & $\begin{array}{c}\text { TV, Video player, } \\
\text { DVD player }\end{array}$ & \\
\hline & $\begin{array}{l}\text { Mesa do } \\
\text { professor }\end{array}$ & & $\begin{array}{l}\text { Câmeras } \\
\text { fotográficas, } \\
\text { Filmadoras }\end{array}$ & \\
\hline & Cavaletes & & Caixas de Som & \\
\hline & & & GPS & \\
\hline & & Tomadas & Lousa Digital & \\
\hline & & Interruptores & Scanner 3D & \\
\hline \multirow{8}{*}{$\begin{array}{c}\text { Sala de Aula } \\
\text { a } \\
\text { Instituição B }\end{array}$} & & & & \\
\hline & & $\begin{array}{l}\text { Quadro } \\
\text { branco }\end{array}$ & Datashow & Datashow \\
\hline & $\begin{array}{l}\text { Pranchetas com } \\
\text { réguas paralelas }\end{array}$ & & Computador & \\
\hline & $\begin{array}{l}\text { Pranchetas com } \\
\text { réguas paralelas }\end{array}$ & & Internet wireless & \\
\hline & $\begin{array}{l}\text { Mesa do } \\
\text { professor }\end{array}$ & & TV & \\
\hline & & Tomadas & DVD & \\
\hline & & Interruptores & Caixas de som & \\
\hline & Tablado & & Extensão & \\
\hline \multirow{8}{*}{$\begin{array}{l}\text { Sala de Aula Y } \\
\text { Instituição B }\end{array}$} & & & & \\
\hline & & $\begin{array}{l}\text { Quadro } \\
\text { branco }\end{array}$ & Datashow & Datashow \\
\hline & $\begin{array}{l}\text { Pranchetas com } \\
\text { réguas paralelas }\end{array}$ & & Computador & $\begin{array}{c}\text { Tela de } \\
\text { projeção }\end{array}$ \\
\hline & Mesa de apoio & & Internet wireless & \\
\hline & $\begin{array}{l}\text { Mesa do } \\
\text { professor }\end{array}$ & & TV & \\
\hline & Tablado & Tomadas & DVD & \\
\hline & & Interruptores & Caixas de som & \\
\hline & & & Extensão & \\
\hline
\end{tabular}

Fonte: Resultado da Pesquisa (2015) 
Da Tabela 1 pode-se aferir que os espaços de aprendizagem nesses cursos de Arquitetura e Urbanismo, objetos de estudo dessa pesquisa, estão sendo adaptados para atender as demandas tecnológicas que estão sendo utilizadas por alunos e professores. Isso foi mais perceptível na instituição A, onde novos equipamentos foram adquiridos e o uso intenso de computadores móveis (laptops) demandaram adaptações na sala de aula.

A arquitetura contemporânea envolve ferramentas computacionais com tecnologia de ponta Fracalossi (2013). De acordo com Carvalho e Savignon (2012) assiste-se a passagem da prancheta analógica para a prancheta digital. Segundo Oliveira e Pereira (2009) o mercado de trabalho no âmbito da Arquitetura e Urbanismo e outros acompanham as transformações da sociedade rapidamente. Papel manteiga, réguas paralelas, estiletes, esquadros, várias canetas com espessuras e outras tecnologias tradicionais estão em extinção na maioria dos escritórios. Oliveira, Pereira e Dandolini (2009) argumentam que o ensino de arquitetura não acompanha essas mudanças com a mesma velocidade por várias razões, sendo uma delas a questão financeira.

Na pesquisa foram observadas tecnologias novas e tradicionais no ambiente de ensino de projeto arquitetônico. As tecnologias tradicionais que compõe o espaço são pranchetas com e sem réguas paralelas, quadro branco, quadro negro de giz, tablado e mesa do professor. Na instituição A não há tablado e nem pranchetas sem réguas paralelas e na $B$ não há quadro negro de giz. As tecnologias novas identificadas foram no ambiente da sala de aula foram datashow, tela para projeção, retroprojetor, internet wireless e ponto de internet, sendo esta não identificada na instituição B. A ausência de computadores desktop no ambiente pode ser pelo fato de cada aluno ter 0 seu computador individual e o professor usar o laptop da instituição.

Foi sancionado em 12 de dezembro de 2007 o decreto número 6.300, o Programa Nacional de Tecnologia Educacional (PROINFO) com o intuito de proporcionar a utilização pedagógica das TICs nas instituições públicas de educação básica. É um programa que contempla a educação básica. O ensino superior e seus espaços das salas de aula não são mencionados no decreto.

Em algumas legislações, a Lei de Diretrizes e Bases da Educação Nacional (LDB), e o Plano Nacional da Educação (PNE), observou-se a questão da tecnologia como um aperfeiçoamento e/ou inovações produzidas pelas IES com o objetivo de produzir tecnologias que visem o crescimento do país. No item da LDB que trata o nível superior de ensino a tecnologia é abordada quando o documento traz a investigação científica e a divulgação da técnica. No Título VII do documento a tecnologia aparece quando são citadas a aquisição, manutenção, construção e conservação de instalação e equipamentos necessários ao ensino. No PNE (Plano Nacional de Educação) a adequação arquitetônica e os recursos das tecnologias são observados quando o PNE trata da educação especial. Para elevar a taxa bruta da educação a nível superior o documento sanciona a otimização da capacidade instalada da estrutura física; o mapeamento da demanda e o apoio a formação pessoal de nível superior destacadamente nas áreas de matemática e ciências observando as necessidades do desenvolvimento do Brasil, as inovações tecnológicas e a melhoria da qualidade da educação básica e outros. 
Nas metas do PNE melhorar a qualidade da educação superior e proporcionar um número maior de mestres e doutores no corpo docente não aparece nenhuma estratégia de ensino relacionada às novas tecnologias e as tradicionais tecnologias.

A Resolução $\mathrm{n}^{\circ}$ 2, de 17 de Junho de 2010 discorre sobre as diretrizes curriculares para 0 curso de Arquitetura e Urbanismo. Na Resolução a informática é bem frisada no documento. O aluno deve ter conhecido dos instrumentos de informática, devem utilizar computadores. A Resolução traz também o emprego de vídeo e fotografia, habilidades em maquetes, modelagens e imagens virtuais para a formação do arquiteto. Mas não discorre com clareza sobre os benefícios da informática no processo ensino aprendizagem do futuro arquiteto e nem como deve ser a arquitetura do espaço das salas de aula.

As tecnologias inseridas no ambiente de ensino de projeto são compostas por tradicionais e novas tecnologias. Essa constatação é entendida aqui como hibridização do espaço. As salas de aula investigadas expressam a necessidade do professor de projeto arquitetônico em tempos atuais de buscar a mediação dos novos recursos tecnológicos no processo ensinoaprendizagem, mas também continuar a utilizar os recursos tradicionais ainda considerados importantes na formação do arquiteto e urbanista.

\section{CONSIDERAÇÕES FINAIS}

Os ambientes das salas de aula precisam de uma redefinição de seus espaços em função da sociedade em que se vive que está em constantes transformações. É necessário que o aluno seja formado dentro de seu contexto social, dentro da realidade em que vive, no caso, uma sociedade em constantes transformações, em constantes avanços tecnológicos. O fato da tecnologia de ponta fazer parte da tecnologia global, as tecnologias tradicionais também vão estar inseridas nos ambientes de aprendizagem tornando-o híbrido.

Observou-se que o simples fato das instalações não estarem adequadas, como a existência de tomadas de energia e pontos de internet ou internet wireless já provocam grandes impactos no processo de ensino. É necessário que os ambientes de ensino continuem se adequando, maximizando as possibilidades de uso para contribuir no processo de ensino-aprendizagem. A reflexão das práticas educacionais é imprescindível para a produção da arquitetura e do urbanismo em tempos de inovadoras tecnologias da comunicação e informação.

No programa PROINFO, de apoio à inserção de novas tecnologias no espaço escolar e as legislações nacionais destinadas à educação não é abordado de maneira clara a eficácia das novas tecnologias no ensino, principalmente no ambiente das salas de aula. A preocupação do Estado em relação à questão das novas tecnologias no espaço no ensino básico é proporcionar a comunidade educacional laboratórios de informática muitas vezes não utilizados. A LDB e o PNE quando abordam as tecnologias no ensino superior é com o propósito de produzir tecnologias que promovam o desenvolvimento do país. A Resolução traz a informática para o processo ensino-aprendizagem do futuro arquiteto e urbanista, mas o intuito maior é o de fornecer laboratórios equipados com microcomputadores. 
A grande discussão nesse período de transição e adaptação tecnológica é a argumentação sobre o desafio de profissionais das áreas de educação e arquitetura e construção para reconhecer as mudanças que poderão ocorrer nos próximos anos, com essa evolução da tecnologia, para assim desenharem ambientes de aprendizagem que irão atender estas demandas.

\section{AGRADECIMENTOS}

À CAPES e ao Grupo de Pesquisa INOVA.

\section{REFERÊNCIAS BIBLIOGRÁFICAS}

BOK, Ana Mercês; FURTADO, Odair; TEIXEIRA, Maria de Lourdes. Psicologias: uma introdução ao estudo de psicologia. São Paulo: Saraiva S.A - Livretos Editores, 2009.

BRASIL. Lei n. 13.005, de 25 de junho de 2014. Plano Nacional de EducaçãoPNE. Lex: Disponível em: <www.planalto.gov.br>. Acesso em: 17 jun. 2015. Lei n. 6.300, de 12 de dezembro de 2007. Programa Nacional de Tecnologia Educacional-PROINFO. Disponível em: <www.planalto.gov.br>. Acesso em: 16 jun. 2015. . Lei n. 9394, de 20 de dezembro de 1996. Estabelece sobre as Diretrizes e Bases da Educação Nacional-LDB. Disponível em: <www.planalto.gov.br>. Acesso em: 17 jun. 2015.

CARVALHO, R.; SAVIGNON, A.. O professor de projeto de arquitetura na era digital: desafios e perspectivas. Gestão e Tecnologia de Projetos. v. 6, n. 2, 2012.

CASTELLS, M. A sociedade em rede. 6 ed. v. 1. São Paulo: Paz e Terra, 1999.

CLEMENTS-CROOME, D. J. What do we mean by intelligent buildings. Automation in Construction 6. p. 396-400, 1997.

CONSELHO NACIONAL DE EDUCAÇÃO. Resolução n. 2, de 17 de junho de 2010: Institui as diretrizes curriculares nacionais do curso de graduação em Arquitetura e Urbanismo alterando dispositivos da Resolução CNE/CES $n^{\circ}$ 6/2006. Disponível em: <www.abea-arq.org.br>. Acesso em: 23 fev. 2014.

CROSBIE, M.J. Class Architecture. Australia: Images Publishing, 2001.

DEPARTMENT FOR EDUCATION AND SKILLS (DFES). Classrooms of the future: innovative designs for schools. Londres: The Stationary Office, 2003.

KENSKI, V. Educação e Tecnologias: o novo ritmo da informação. Campinas: Papirus, 2007.

KOWALTOWSKI, D. C.C.K. Arquitetura escolar: o projeto do ambiente de ensino. 1 ed. São Paulo: Oficina de Textos, 2011.

MALARD, M. L. Cinco textos sobre arquitetura. Belo Horizonte: UFMG, 2005.

FRACALOSSI, Igor. Fundamentos da arquitetura contemporânea / Siegbert Zanettini, (2013). Disponível em: <www.archdaily.com.br>. Acesso em: 25 de Janeiro de 2015. 
MONTEBELLER, S. J. Sensores sem fio: Avaliação e emprego na automação de sistemas prediais, 2011. Disponível em: < www.books.google.com.br >. Acesso em: 04 mai. 2013.

OLIVEIRA, L., PERERIA, A., DANDOLINI, G., VANZIN, T. Arquitetura - ensino e prática projetual: as mudanças tecnológicas e seus desdobramentos. In: Congresso Nacional de ambientes: hipermídias para a aprendizagem, Florianópolis. Anais... n. 4, p. 2-12, nov. 2009.

PÁDUA, I. H. Caracterização de Edifícios Inteligentes: um caso exemplo. 2006. 110f. Dissertação (Mestrado em Engenharia Elétrica) - Programa de Pós Graduação em Engenharia Elétrica da Pontifícia Universidade Católica de Minas Gerais, Belo Horizonte.

PROSHANSKY, H., ITTELSON, W., RIVLIN, L. Psicología ambiental: el hombre y su entorno físico. México: Editorial Trillas, 1978.

SEGUNDO, M., ROMANO, E. O Computador e o Ensino de Projeto Arquitetônico: revisando a questão nos seminários projetar. TEMA, Revista Eletrônica de Ciências. v.10, $n^{\circ}$ 15, 2010.

SPELLER, P., ROBL, F., MENEGHEL, S. Desafios e perspectivas da educação superior brasileira para a próxima década. Brasília: UNESCO, CNE, MEC, 2012.

TIBÚRCIO, T. O impacto de novas tecnologias no ambiente de aprendizagem. Simpósio Brasileiro de Qualidade do Projeto no Ambiente Construído. Anais... São Carlos, 2009, p. 703-713.

TIBÚRCIO, T., GONZAGA, T., ROCHA, K. O espaço de aprender sob o olhar de novas tecnologias: avaliação de salas de aula de uma instituição federal de ensino. Qualidade de Projeto na Era Digital Integrada. Campinas, 2013.

TIBÚRCIO, T., PIERONI, N., COSTA, T. O ambiente de trabalho contemporâneo: tecnologias e sistemas inteligentes na arquitetura de escritórios. Qualidade de Projeto na Era Digital Integrada. Campinas, 2013.

VILELA, C., ABECÊ, F., PAULA, G. et. al. Curso de graduação em Arquitetura e Urbanismo/Projeto Político Pedagógico, 2008. Disponível em: <www.em.ufop.com.br>. Acesso em: 30 nov. 2013. 